\title{
Cool response to Durban compromise
}

\author{
The Durban conference on climate change made progress of sorts, but the hardest decisions have \\ been deferred.
}

Maite Nkoana-Mashabane, president of the 2011 United Nations Framework Convention on Climate Change conference held in Durban, South Africa, has declared the outcome of the protracted and fraught negotiations a success. As a former activist during South Africa's apartheid era and a present member of the National Executive Committee of the African National Congress, she must know that changing hearts and minds to achieve real progress in any political sphere can be a drawn-out and frustrating process - and so it is with climate change negotiations.

True, as discussed by Jeff Tollefson (page 66), the Durban conference ended in December with a commitment to prepare a legally binding treaty on carbon emissions by 2015 - the so-called Durban Platform and with the creation of a substantial Green Climate Fund to finance adaptation measures in the world's poorest countries. It is also good news that the United States - never a signatory of the Kyoto Protocol - along with major emerging economic players such as India and China seem willing to play their part. But many feel that an opportunity to make greater and more immediate progress has been missed, leaving a dangerous hiatus between the end of the first Kyoto commitment period later in 2012 and the full implementation of a new global climate agreement, assuming that such a thing materializes by 2020 as intended. Although the European Union will maintain its commitments under the Kyoto Protocol, some major nations seem content to drag their heels in negotiations, and to the derision of environmental lobbyists, Canada has withdrawn from the protocol altogether.

One way or another, the protocol will limp on until 2018 or so, but the likelihood of avoiding global warming in excess of $2{ }^{\circ} \mathrm{C}$ seems increasingly remote. The Intergovernmental Panel on Climate Change (IPCC) recently warned that the expected consequent increase in the frequency and intensity of extreme weather events will take its toll in terms of both human well-being and economic impacts. IPCC assessment reports summarize the latest scientific consensus on climate change and its likely impacts, along with options for mitigation and adaptation. However, they have changed from being relatively straightforward briefing documents for policymakers, as originally envisaged.
They now delve into every aspect of climate change, often in intoxicating detail, and receive input from literally thousands of scientists and others.

Some feel that the whole process has become overly cumbersome. In December, Stanford-based atmospheric scientist Ken Caldeira of the Carnegie Institution for Science resigned as a lead author of the IPCC's fifth assessment report, due to be completed in 2014 . He is quoted as saying that "clearly, at the outset, the early IPCC reports played an important role showing that there was a high degree of consensus around the reality and basic science of humaninduced climate change". After questioning whether any important positive outcomes came out of the previous report's process and the prospects of the process for the fifth fairing better, he went on to say: "I am all for scientific reviews and assessments, and I think the multi-model comparisons reviewed by the IPCC have been especially useful. However, it is not clear how much additional benefit there is to having a huge bureaucratic scientific review effort under United Nation auspices .... This will ring true to many of those involved in the debate.

We hope that those disinclined to delve into the nitty-gritty of climate change as documented by the IPCC will nevertheless find much of interest in Nature Climate Change to get their teeth into. Among the interesting and sometimes controversial topics covered by the research papers in this issue of the journal is that of geoengineering. Scientists warn that if humanity fails to get greenhouse-gas emissions under control, it may one day become necessary to intervene actively in the Earth system. One widely discussed option is solar-radiation management (SRM), an example of which would be the injection of large amounts of sulphurous aerosols into the stratosphere to reflect incoming solar radiation. On page 92 , Katharine Ricke and co-workers examine the effects of global temperature stabilization through SRM-based geoengineering. Their computer simulations suggest that the success of SRM as an alternative to or a mechanism to delay mitigation will be lower if the climate's sensitivity to greenhouse gases is high, but that the potential of SRM to offset the effects of climate change under increasing greenhouse-gas concentrations grows with climate sensitivity.
Of course, the very idea of deliberately manipulating the planetary environment on the scale necessary to cool the planet brings chills to the spine, and models now suggest strong tension between the objectives to reduce the rate of temperature change and sea-level rise (page 97). However, another modelling study shows that solar-radiation geoengineering in a high-carbon-dioxide climate may not harm global crop yields (page 101). Further research is necessary if we are to understand the potential consequences of the geoengineering options so far proposed, and that will have to involve empirical experiments.

The best hope of avoiding the eventual need for geoengineering is to cut greenhousegas emissions radically. Sonja van Renssen (page 71) discusses how developing nations are striving to do this voluntarily, and what richer countries need to do to support and encourage their efforts. In another article, Anna Petherick (page 72) examines the role of banks in facilitating global warming through their investments in coal, which, we learn, have actually doubled since 2005. A startling message is that banks are often unaware just how much capital they have tied up in the industry.

Burning vast amounts of coal, gas and oil would of course be less necessary if we moved to an energy-efficient economy based primarily on renewable energy. In an interview (page 69), Karen Ehrhardt-Martinez, director of the Climate, Mind and Behavior Program at New York's Garrison Institute offers her view that society can significantly reduce energy consumption through more enlightened behaviour. But how society might achieve a full-blown 'energy revolution' is the subject of a new book by scholar Jeremy Rifkin reviewed on page 67. Part of any such transformation in energy production, distribution and consumption is likely to impact the building industry, a major user of energy and producer of carbon dioxide. On page 62, Jorge Contreras and colleagues discuss the benefits of standardized, transparent and inter-comparable certification criteria for sustainable building materials.

As for climate negotiations, all eyes will now be on the next major United Nations Framework Convention on Climate Change conference (COP18/CMG8) in Doha, Qatar, where the Durban Platform will be put to its first real test. 